\title{
The Learning Curve of Cholesteatoma Surgery: Follow up of Audiological Results
}

\author{
Milan Stankovic ${ }^{1 *}$, Rade Kosanovic ${ }^{2}$ and Petar Stankovic ${ }^{2}$ \\ ${ }^{1}$ University ORL Clinic, Clinical Center Nis, Serbia \\ ${ }^{2} \mathrm{ORL}$ Clinic, KBC Zvezdara, Belgrade, Serbia
}

\begin{abstract}
Objective: To review the effect of learning curve on the audiological results of patients surgically treated for cholesteatoma.
\end{abstract}

Study design: Retrospective review of patients records in tertiary referral center.

Patients: Retrospective study of 758 patients operated by one surgeon for acquired middle ear cholesteatoma divided into two periods. The patients were divided into three age groups: children, adolescents, and adults. The localization of cholesteatoma was classified as: attic, sinus, or tensa. Audiological results were followed during shortterm and long-term period.

Interventions: Patients were treated with single canal wall up or wall down, according to the propagation of disease and condition of middle ear. Reoperations were performed when needed.

Main outcome measures: Preoperative and postoperative air bone gap (ABG) was compared in different groups.

Results: In short term follow up the surgical experience was found significant for: attic and sinus tympani site, adult patients, absent manubrium mallei, closed technique, unilateral cholesteatoma, and primary surgery. During long tem follow up experience resulted in better audiological results for: all sites of cholesteatoma, adolescents and adults, all types of ossicular damage, uni- and bilateral cholesteatoma, for closed technique, and both for primary and revision operations.

Conclusion:Obtained experience during surgical treatment for cholesteatoma was significantly influential on the improvement of audiological results of different aspects of cholesteatoma elimination, particularly for difficult and advanced cases, such as attic cholesteatoma, bigger ossicular damage, and closed surgical technique.

Keywords: Tympanoplasty; Cholesteatoma; Air bone gap; Attic; Sinus; Tensa; Age; Experience

\section{Introduction}

This improvement of audiological results after cholesteatoma surgery is influenced by many factors, such as age, type and localization of pathological process in middle ear, status of Eustachian tube, skill of the surgeon and used surgical technique [1,2].

The follow-up period in tympanoplasty be classified as preliminary (under one year), short-term (1-5 years), or long-term (over five years). The reports on long-term observations are rare, and during time the surgeon may change the surgical technique. The accumulated surgical experience may significantly improve the results [3-5].

The aim of the present study is to analyze the effect of learning curve on the audiological results of cholesteatoma surgery.

\section{Patients and Methods}

Retrospective study of 758 patients operated for acquired middle ear cholesteatoma during the period 1990-2002 was performed. They were divided into two groups with equal number of patients: the first surgical period and the second surgical period with more experience. The patients were followed during short-term period (one year after the operation, and during long-term period (more than five years after the operation).

The purpose, principles, and potential complications of surgery were explained to the patients, or parents, and they accepted them. The patients were divided into three age groups: children under nine, adolescents - ten to 16 years, and adults (4). The localization of cholesteatoma was classified as: attic, sinus, or tensa [5]. The types of damage of auditory ossicles were: malleus and stapes present $(\mathrm{M}+\mathrm{S}+)$, malleus present, stapes absent $(\mathrm{M}+\mathrm{S}-)$, malleus absent, stapes present (M-S+), and malleus and stapes absent (M-S-) [6].

All the tympanoplasties were carried out by the same surgeon. Closed tympanoplasty was always performed as single procedure of choice on all the children, and reoperation (recurrent cholesteatoma, resuppuration, and $\mathrm{AB}$ gap more than $20 \mathrm{~dB}$ ) or conversion to open tympanoplasty (inability to control disease using closed technique) was made later if needed. Adult patients were treated with single classical canal wall up, or wall down, according to the propagation of disease and condition of middle ear. Extensive disease, small mastoid, and damaged posterior wall were the main indications for wall down surgery, while in all other cases closed technique was employed. Manubrium mallei and stapedial suprastucture, when present, were preserved, and used for better hearing results by supporting shaped autologous incus. In cases with significantly ostitic incudes they were removed and interposition was performed using tragal cartilage. Reconstruction of attic or reinforcement of tympanic membrane in other parts was made with palisade conchal cartilage [7]. Indications for reoperations were the same.

*Corresponding author: Milan Stankovic, University ORL Clinic, Clinical Center Nis Bul dr Zorana Djindjica48, 18000 Nis, Serbia, E-mail: milanorlstankovic@gmail.com

Received December 15, 2012; Accepted April 29, 2013; Published May 07, 2013

Citation: Stankovic M, Kosanovic R, Stankovic P (2013) The Learning Curve of Cholesteatoma Surgery: Follow up of Audiological Results. Surgery S12: 016. doi:10.4172/2161-1076.S12-016

Copyright: () 2013 Stankovic M, et al. This is an open-access article distributed under the terms of the Creative Commons Attribution License, which permits unrestricted use, distribution, and reproduction in any medium, provided the original author and source are credited. 
Hearing results were reported according to the American Academy of Otolaryngology-Head and Neck Surgery Committee of Hearing and Equilibrium guidelines for the evaluation of results of treatment of conductive hearing loss. Hearing results were measured for air bone gap (ABG), and pure tone average (PTA). Successful hearing was defined as a postoperative ABD of $20 \mathrm{~dB}$ or less, and PTA of $30 \mathrm{~dB}$ or less. ABG and PTA were analyzed at .5, 1, 2, and $3 \mathrm{kHz}[8]$. The mean of the four frequencies produced an ABG or PTA value. ABG at 4 and 6 $\mathrm{kHz}$ vas also measured for analyze of hearing outcome. Type of surgical therapy, localization of cholesteatoma, age of patients, revisions, bilaterality of disease, damage of auditory ossicles and learning curve were analyzed.

Paired $t$ test was used to investigate the differences between groups ( $\mathrm{p}$ value less than 0.05 represented statistically significant differences).

\section{Results}

No significant difference was verified for the localization of cholestatoma and preoperative audiogram in these groups. The second period gave improvement for attic and sinus tympani for the short term period, while in the long term better audiological results were found for all the groups (Table 1).

The most of the patients with cholesteatoma were older than 16 years. Preoperative audiometry was equally distributed in different age groups. Surgical experience was only evidenced in adults after short and long term observation and for adolescents in the short term (Table 2).

Damage of auditory ossicles was variable, so present both malleus and stapes were present in $43.7 \%$, while the absence of stapes suprastructure was verified in $41.8 \%$, but without direct connection to preoperative audiometry. Learning curve confirmed both short and long term better results in more advanced ossicular damage (Table 3 ).

Closed technique was more frequently used in both periods, totally in $60.6 \%$. Surgical experience resulted in significant audiological improvement only for closed technique, both for short and long term follow-up (Table 4).

Revision cholesteatoma operations were performed in $8.4 \%$ of patients in the analyzed period, mainly in the second period (Figures 1-3). The reoperations were more frequent after longer observation of patients. Surgical experience was proven important both for primary and revision interventions (Table 5).

Blateral cholesteatoma was present in $6.2 \%$ of cases, and accumulated knowledge was more influential in unilateral cholesteatoma (Table 6).

\section{Discussion}

The long-term audiological results of tympanoplasty are not as good as the short-term results. The degree of otorrhoea, the status of auditory ossicles, tympanic membrane perforation, middle ear

\begin{tabular}{|c|c|c|c|c|c|c|c|}
\hline \multicolumn{2}{|c|}{ Group } & \multirow[b]{2}{*}{ No } & \multirow[b]{2}{*}{ Preoperative } & \multicolumn{2}{|c|}{ Short term } & \multicolumn{2}{|c|}{ Long term } \\
\hline & Period & & & Postoperative & $\Delta \mathbf{d B}$ & Postoperative & $\Delta \mathrm{dB}$ \\
\hline \multirow[t]{2}{*}{ ATTIC } & I & 152 & $31.2 \pm 8.5$ & $13.5 \pm 5.2$ & 17.7 & $16.7 \pm 9.7$ & 14.5 \\
\hline & II & 179 & $30.5 \pm 8.1$ & $7.2 \pm 4.6^{*}$ & 23.3 & $10.8 \pm 5.1^{*}$ & 19.7 \\
\hline \multirow[t]{2}{*}{ SINUS } & I & 125 & $32.4 \pm 9.1$ & $12.8 \pm 5.8$ & 19.6 & $15.2 \pm 7.1$ & 17.2 \\
\hline & II & 104 & $28.6 \pm 8.7$ & $11.0 \pm 7.6$ & 17.6 & $12.0 \pm 5.9^{*}$ & 16.6 \\
\hline \multirow[t]{2}{*}{ TENSA } & I & 102 & $33.1 \pm 8.9$ & $14.4 \pm 7.1$ & 18.7 & $18.9 \pm 10.4$ & 14.2 \\
\hline & II & 96 & $33.3 \pm 11.8$ & $11.4 \pm 4.1^{*}$ & 21.9 & $13.2 \pm 6.5^{*}$ & 20.1 \\
\hline
\end{tabular}

* = significantly different $(p<0.05)$

Table 1: Postoperative air-bone gap $(\mathrm{dB})$ and the site of cholesteatoma

\begin{tabular}{|c|c|c|c|c|c|c|c|}
\hline \multicolumn{2}{|c|}{ Group } & \multirow[b]{2}{*}{ No } & \multirow[b]{2}{*}{ Preoperative } & \multicolumn{2}{|c|}{ Short term } & \multicolumn{2}{|c|}{ Long term } \\
\hline & Period & & & Postoperative & $\Delta \mathbf{d B}$ & Postoperative & $\Delta \mathrm{dB}$ \\
\hline \multirow[t]{2}{*}{$0-9 y$} & I & 18 & $29.4 \pm 10.8$ & $14.9 \pm 9.2$ & 14.5 & $17.5 \pm 11.4$ & 11.9 \\
\hline & II & 24 & $27.7 \pm 11.9$ & $12.1 \pm 7.4$ & 15.6 & $15.3 \pm 9.2$ & 12.9 \\
\hline \multirow[t]{2}{*}{$10-16 y$} & I & 27 & $31.7 \pm 9.6$ & $13.1 \pm 6.3$ & 18.6 & $18.0 \pm 9.9$ & 13.7 \\
\hline & II & 31 & $30.8 \pm 10.7$ & $11.2 \pm 7.8$ & 19.6 & $13.2 \pm 8.5^{\star}$ & 17.6 \\
\hline \multirow[t]{2}{*}{$>16 y$} & I & 334 & $32.3 \pm 8.6$ & $13.5 \pm 5.7$ & 18.8 & $17.2 \pm 8.4$ & 15.1 \\
\hline & II & 324 & $30.9 \pm 8.9$ & $8.9 \pm 4.9^{*}$ & 22.0 & $12.5 \pm 6.1^{*}$ & 18.4 \\
\hline
\end{tabular}

* $=$ significantly different $(p<0.05)$

Table 2: Postoperative air-bone gap $(\mathrm{dB})$ and the age of patients.

\begin{tabular}{|c|c|c|c|c|c|c|c|}
\hline \multicolumn{2}{|c|}{ Group } & \multirow[b]{2}{*}{ No } & \multirow[b]{2}{*}{ Preoperative } & \multicolumn{2}{|c|}{ Short term } & \multicolumn{2}{|c|}{ Long term } \\
\hline & Period & & & Postoperative & $\Delta \mathrm{dB}$ & Postoperative & $\Delta \mathrm{dB}$ \\
\hline \multirow[t]{2}{*}{$\mathrm{M}+\mathrm{S}+$} & I & 175 & $30.6 \pm 8.4$ & $9.9 \pm 5.4$ & 20.7 & $11.3 \pm 6.2$ & 19.3 \\
\hline & II & 156 & $30.8 \pm 8.8$ & $8.5 \pm 2.6$ & 22.2 & $9.5 \pm 5.1^{*}$ & 21.3 \\
\hline \multirow[t]{2}{*}{ M+S- } & I & 93 & $31.5 \pm 9.1$ & $11.2 \pm 4.8$ & 20.3 & $15.1 \pm 6.3$ & 16.4 \\
\hline & II & 107 & $30.6 \pm 7.2$ & $10.6 \pm 6.9$ & 20.0 & $12.3 \pm 5.6^{*}$ & 18.3 \\
\hline \multirow[t]{2}{*}{ M-S+ } & I & 52 & $33.8 \pm 11.2$ & $20.0 \pm 5.3$ & 17.1 & $23.5 \pm 11.3$ & 10.3 \\
\hline & II & 58 & $33.4 \pm 8.9$ & $10.5 \pm 8.1^{*}$ & 22.9 & $14.7 \pm 6.3^{*}$ & 19.7 \\
\hline \multirow[t]{2}{*}{ M-S- } & I & 59 & $36.0 \pm 7.4$ & $19.9 \pm 9.6$ & 11.0 & $25.4 \pm 9.7$ & 10.6 \\
\hline & II & 58 & $31.9 \pm 13.9$ & $13.2 \pm 6.8^{*}$ & 18.7 & $18.2 \pm 9.2^{*}$ & 13.7 \\
\hline
\end{tabular}

* $=$ significantly different $(p<0.05)$

Table 3: Postoperative air-bone gap $(\mathrm{dB})$ and the status of auditory ossicles $(\mathrm{M}=$ malleus, $\mathrm{S}=$ stapes, $+=$ present, $-=$ absent $)$. 


\begin{tabular}{|c|c|c|c|c|c|c|c|}
\hline \multicolumn{2}{|c|}{ Group } & \multirow[b]{2}{*}{ No } & \multirow[b]{2}{*}{ Preoperative } & \multicolumn{2}{|c|}{ Short term } & \multicolumn{2}{|c|}{ Long term } \\
\hline & Period & & & Postoperative & $\Delta \mathbf{d B}$ & Postoperative & $\Delta \mathrm{dB}$ \\
\hline \multirow[t]{2}{*}{ ICW } & I & 201 & $31.6 \pm 9.4$ & $14.9 \pm 5.7$ & 16.7 & $17.7 \pm 5.9$ & 13.9 \\
\hline & II & 258 & $30.5 \pm 8.5$ & $8.0 \pm 5.0^{*}$ & 22.5 & $13.1 \pm 7.7^{*}$ & 17.4 \\
\hline \multirow[t]{2}{*}{ CWD } & I & 178 & $32.7 \pm 8.1$ & $11.9 \pm 6.1$ & 20.0 & $19.3 \pm 11.4$ & 13.4 \\
\hline & II & 121 & $31.1 \pm 10.7$ & $12.1 \pm 5.9$ & 19.0 & $18.4 \pm 9.2$ & 12.7 \\
\hline
\end{tabular}

* = significantly different $(p<0.05)$

Table 4: Postoperative air-bone gap $(\mathrm{dB})$ and the type of surgical technique (ICW $=$ intact canal wall, $C W D=$ canal wall down technique).

\begin{tabular}{|c|c|c|c|c|c|c|c|}
\hline \multicolumn{2}{|c|}{ Group } & \multirow[b]{2}{*}{ No } & \multirow[b]{2}{*}{ Preoperative } & \multicolumn{2}{|c|}{ Short term } & \multicolumn{2}{|c|}{ Long term } \\
\hline & Period & & & Postoperative & $\Delta \mathrm{dB}$ & Postoperative & $\Delta \mathrm{dB}$ \\
\hline \multirow[t]{2}{*}{ Primary } & I & 356 & $32.0 \pm 8.6$ & $13.3 \pm 5.8$ & 18.7 & $17.5 \pm 9.3$ & 14.5 \\
\hline & II & 338 & $30.5 \pm 8.9$ & $8.9 \pm 4.7^{*}$ & 21.6 & $11.4 \pm 8.2^{*}$ & 19.1 \\
\hline \multirow[t]{2}{*}{ Revision } & I & 23 & $33.5 \pm 12.2$ & $16.8 \pm 7.1$ & 16.7 & $23.5 \pm 11.1$ & 10.0 \\
\hline & II & 41 & $33.0 \pm 11.2$ & $12.6 \pm 9.9^{*}$ & 20.4 & $18.6 \pm 9.0^{*}$ & 14.4 \\
\hline
\end{tabular}

* $=$ significantly different $(p<0.05)$

Table 5: Postoperative air-bone gap $(\mathrm{dB})$ and primary vs. revision surgery.

\begin{tabular}{|c|c|c|c|c|c|c|c|}
\hline \multicolumn{2}{|c|}{ Group } & \multirow[b]{2}{*}{ No } & \multirow[b]{2}{*}{ Preoperative } & \multicolumn{2}{|c|}{ Short term } & \multicolumn{2}{|c|}{ Long term } \\
\hline & Period & & & Postoperative & $\Delta \mathbf{d B}$ & Postoperative & $\Delta \mathrm{dB}$ \\
\hline \multirow[t]{2}{*}{ Unilateral } & I & 358 & $32.0 \pm 8.8$ & $13.2 \pm 5.8$ & 18.8 & $15.5 \pm 6.9$ & 16.5 \\
\hline & II & 353 & $30.6 \pm 8.6$ & $8.6 \pm 5.2^{*}$ & 22.0 & $12.4 \pm 7.3^{*}$ & 18.2 \\
\hline \multirow[t]{2}{*}{ Bilateral } & 1 & 21 & $33.1 \pm 9.2$ & $18.0 \pm 7.4$ & 15.1 & $24.1 \pm 8.3$ & 9.1 \\
\hline & II & 26 & $32.2 \pm 11.7$ & $18.3 \pm 6.9$ & 15.9 & $19.1 \pm 7.3^{*}$ & 13.1 \\
\hline
\end{tabular}

* = significantly different $(p<0.05)$

Table 6: Postoperative air-bone gap $(\mathrm{dB})$ and unilateral vs. bilateral disease.

mucosa, cholesteatoma, experience of the surgeon, re-aeration of the reconstructed middle-ear cavity, and presumed incomplete removal are considered important for the success [9].

The preoperative air-bone gap does not significantly correlate with ossicular discontinuity. The cholesteatoma and granulation tissue in the middle ear cavity may serve as transmission bridges of acoustic energy, resulting in smaller air-bone gaps.

Both cholesteatoma extension into the tympanic sinus and persistently draining ears are predictive of ossicular discontinuity. Also, poor hearing before surgery is associated with poor hearing after surgery, regardless of anatomy and type of Tympanoplasty $[5,9,10]$.

Both Intact Canal Wall (ICW) and Canal Wall Down (CWD) techniques are used for surgical treatment of cholesteatoma. Audiological results support the continued use of ICW mastoidectomy with tympanoplasty. CWD mastoidectomy with tympanoplasty provides a safe ear and good hearing results $[9,10]$.

The learning curve for different cholesteatoma localizations is mainly produced by proper elimination of cholesteatoma, better reconstruction of ossicular system, reconstruction of atticotomy, insertion of ventilation tube for advanced tensa cholesteatoma. This all results in significantly and long term improved postoperative hearing.

The results of this study confirm the difficulty of surgical treatment of pediatric cholesteatoma, with higher recurrent rate, the need for long-term follow up, and revision surgery. The absence of postoperative hearing improvement in adolescents, and particularly in children, contrary to obvious improvement in adults reflects the persistent adverse activity of upper respiratory tract infections. So, experience can not lead to retaining of audiological results of cholesteatoma surgery in children [10-14].

When present and healthy autologous incus is preferred ossiculoplasty material $[1,3]$. We found out that hearing results of autologous ossiculoplasty without recurrent disease were long-term stable, without statistical difference from the short-term results. Damage of auditory ossicles in cholesteatoma only partially correlates to preoperative audiometry because of mass effect and different combinations of the influence of pathological process. The improvement of hearing that goes with surgical experience is particularly present when ossicles are badly damaged. Proper elimination of pathology, as well as adequate reconstruction of ossicular defect achieved by increased knowledge is particularly evident in difficult reconstruction cases (absence of manubrium mallei and stapedial suprastructure) $[7,11]$.

Attic reconstruction with cartilage gives good results in preventing postoperative retraction pockets. Routine reconstruction of attic with cartilage resulted in low postoperative level of recurrent disease in this series of patients [15].

Accumulated surgical knowledge gave better audiological results for closed surgical technique which is more demanding. Probably the improvement in open surgical technique, should be also present, however the advanced pathology and bad tubal function have lower hearing effect.

According to some otosurgeons the functional hearing results of revision surgery for chronic otitis media with cholesteatoma during a long-term follow-up period are similar to primary cases [16-18]. Revision operations depend on the intensity of cholesteatoma, and the time of observation. Recurrent or residual cholesteatoma, as well as insufficient ossicular reconstructions were the main indications, and experience was significantly influential.

In bilateral cholesteatoma cases surgical experience was less evident, as the consequence of bad tubal function [16-19].

Strict reporting protocols, comparison of clinical studies, and longterm follow up could further clarify the importance of some prognostic 


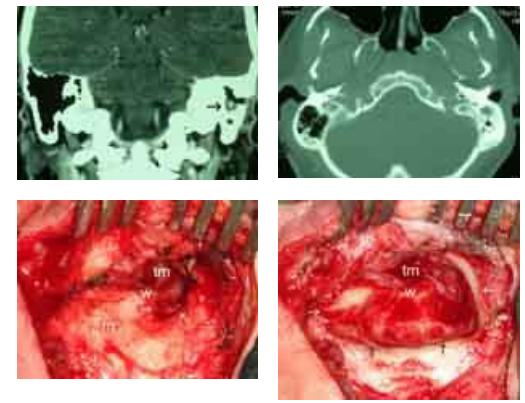

Figure 1: a) and b) CT after previous tympanoplasty, incomplete mastoidectomy $\left({ }^{*}\right)$, granulation tissue $(\rightarrow)$. c) Intraoperative view of partial mastoidectomy, margins $(\rightarrow)$, tympanic membrane $(\mathrm{tm})$, posterior wall $(\mathrm{w})$, mastoid $(\mathrm{m})$. d Completion of mastoidectomy.
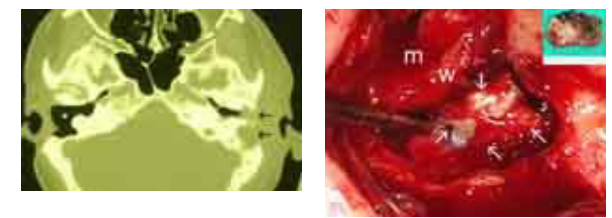

Figure 2: a) CT after previous wall up tympanoplasty, destruction of bony wall by recurrent cholesteatoma $(\rightarrow)$, oposite ear after two previuos tympanoplastises, wall down $(*)$. b)Intraoperative view, limits of recurrent cholesteatoma $(\rightarrow)$ posterior wall $(w)$, meatus $(m)$, cholesteatoma in upper right corner
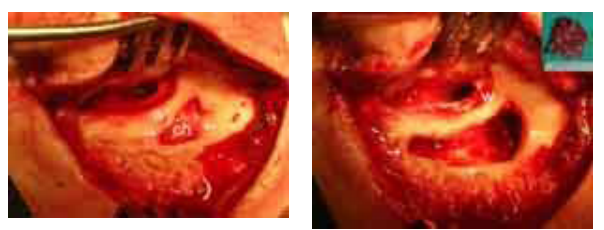

Figure 3: a) Intraoperative picture after four previous unsuccessfull wal up tympanoplasties, partial mastoidectomy $(\rightarrow)$, recurrent cholesteatoma (ch), posteriour wall (w). b) Completion of mastoidectomy and removal of cholesteatoma (upper right corner)

factors and thus improve the success rate of tympanoplasties. Statistical study of different influential factors for the success of cholesteatoma surgery enabled precise documentation of their individual or combined contribution to hearing outcome of tympanoplasties.

The learning curve was especially important for advanced disease with marked damage of auditory ossicles, and for more demanding cases, such as attic cholesteatoma treated with ICW technique (atticotomy and attic reconstruction).

\section{Conclusion}

Experience during surgical treatment for cholesteatoma was significantly influential on the improvement of audiological results of cholesteatoma elimination and reconstruction of middle ear, particularly for difficult and advanced cases, such as attic cholesteatoma, bigger ossicular damage, and closed surgical technique.

\section{References}

1. Yung M (2006) Long-term results of ossiculoplasty: reasons for surgical failure Otol Neurotol 27: 20-26.

2. De Vos C, Gersdorff M, Gérard JM (2007) Prognostic factors in ossiculoplasty Otol Neurotol 28: 61-67.

3. Leonetti JP, Marzo SJ, Beauchamp MM, Jellish WS (2006) Long-term results with operated sinus tympani retraction cholesteatoma. Otolaryngol Head Neck Surg 135: 152-154.

4. Schuring AG, Lippy WH, Rizer FM, Schuring LT (1990) Staging fo cholesteatoma in the child, adolescent, and adult. Ann Otol Rhinol Laryngo 99: 256-260.

5. Tos M, Lau T (1989) Late results of surgery in different cholesteatoma types ORL J Otorhinolaryngol Relat Spec 51: 33-49.

6. lurato S, Marioni G, Onofri M (2001) Hearing results of ossiculoplasty in AustinKartush group A patients. Otol Neurotol 22: 140-144.

7. Stankovic M (2007) Follow-up of cholesteatoma surgery: open versus closed tympanoplasty. ORL J Otorhinolaryngol Relat Spec 69: 299-305.

8. (1995) Committee on Hearing and Equilibrium guidelines for the evaluation of results of treatment of conductive hearing loss. AmericanAcademy of Otolaryngology-Head and Neck Surgery Ffoundation, Inc. Otolaryngol Head Neck Surg 113: 186-187.

9. Ikeda M, Yoshida S, Ikui A, Shigihara S (2003) Canal wall down tympanoplasty with canal reconstruction for middle-ear cholesteatoma: post-operative hearing cholesteatoma recurrence, and status of re-aeration of reconstructed middleear cavity. J Laryngol Otol 117: 249-255.

10. De Corso E, Marchese MR, Scarano E, Paludetti G (2006) Aural acquired cholesteatoma in children: surgical findings, recurrence and functional results. Int J Pediatr Otorhinolaryngol 70: 1269-1273.

11. Kos MI, Castrillon R, Montandon P, Guyot JP (2004) Anatomic and functional long-term results of canal wall-down mastoidectomy. Ann Otol Rhinol Laryngol 113: 872-876.

12. Siddiq MA, East DM (2004) Long-term hearing results of incus transposition Clin Otolaryngol Allied Sci 29: 115-118.

13. McRackan TR, Abdellatif WM, Wanna GB, Rivas A, Gupta N, et al. (2011) Evaluation of second look procedures for pediatric cholesteatomas. Otolaryngo Head Neck Surg 145: 154-160.

14. Visvanathan V, Kubba $\mathrm{H}$, Morrissey MS (2012) Cholesteatoma surgery in children: 10-year retrospective review. J Laryngol Otol 126: 450-453.

15. Anderson J, Cayé-Thomasen P, Tos M (2004) A comparison of cartilage palisades and fascia in tympanoplasty after surgery for sinus or tensa retraction cholesteatoma in children. Otol Neurotol 25: 856-863.

16. Kaylie DM, Gardner EK, Jackson CG (2006) Revision chronic ear surgery. Otolaryngol Head Neck Surg 134: 443-450.

17. Cho YS, Hong SD, Chung KW, Hong SH, Chung WH, et al. (2010) Revision surgery for chronic otitis media: characteristics and outcomes in comparison with primary surgery. Auris Nasus Larynx 37: 18-22.

18. Berçin S, Kutluhan A, Bozdemir K, Yalçiner G, Sari N, et al. (2009) Results of revision mastoidectomy. Acta Otolaryngol 129: 138-141.

19. Park KT, Song JJ, Moon SJ, Lee JH, Chang SO, et al (2011) Choice of approach for revision surgery in cases with recurring chronic otitis media with cholesteatoma after the canal wall up procedure. Auris Nasus Larynx 38: 190195. 